\title{
The LECTOR Podium. An Innovative Teacher Workstation for the Intelligent Classroom of the Future
}

\author{
Helen Stefanidi \\ Institute of Computer Science (ICS), \\ Foundation for Research and \\ Technology - Hellas (FORTH)
}

\author{
Maria Korozi \\ Institute of Computer Science (ICS), \\ Foundation for Research and \\ Technology - Hellas (FORTH)
}

\author{
Asterios Leonidis \\ Institute of Computer Science (ICS), \\ Foundation for Research and \\ Technology - Hellas (FORTH)
}

\author{
Margherita Antona \\ Institute of Computer Science (ICS), \\ Foundation for Research and \\ Technology - Hellas (FORTH)
}

George Papagiannakis

Institute of Computer Science (ICS),

Foundation for Research and

Technology - Hellas (FORTH) and

University of Crete, Greece

Teacher Workstation for the Intelligent Classroom of the Future. In 2020 12th International Conference on Education Technology and Computers (ICETC'20), October 23-26, 2020, London, United Kingdom. ACM, New York, NY, USA, 7 pages. https://doi.org/10.1145/3436756.3437033

\section{INTRODUCTION}

Information and communication technologies (ICTs) have altered the way we access, search and present information [19]. Particularly, in the domain of education, their impact has already been established and continues to grow, generating a particular research interest. Students using ICT facilities [14] reveal increased lesson involvement, greater responsibility as well as higher learning gains. This has caused a fundamental shift of the teacher's role inside the classroom, which is not limited to transmitting knowledge, but also involves supporting, advising and coaching students. Additionally, the domain of education has not been immune to the emergence of the Internet of Things (IoT). Studies have shown that by enhancing the classroom's physical objects, sensors and controllers with Internet based communications (e.g., embedding sensors in objects, augmented reality, wearables), various useful information about the educational environment can be collected and analyzed [2]. Acquiring this information enhances personalized learning by enabling the lecturer to increase student engagement and to focus their attention on students who need further instructions.

In recent years, there have been many research endeavors to intelligently enhance classroom workspaces. According to researchers, adjusting objects from passive to active elements in educational environments supports the teaching-learning process by helping teachers have a better understanding of the learning process and provide more accurate feedback to students [13].

This paper proposes a system, named LECTOR Podium, which aims to constitute a comfortable and flexible workspace for the educator, enabling the control of the ambient facilities in the "smart" educational environment. In addition to its innovative form factor that aims to improve its overall functionality and usability, the accompanying software framework permits the educator to supervise the students and easily manipulate the intelligent artefacts with the objective of improving the learning process.

Concerning the structure of this paper, in Section 2, related work is discussed, while Section 3 presents the design process followed. In Section 4 the look, location and hardware of LECTOR Podium are 
described, whereas in Section 5 the system's software infrastructure is presented. Moreover, Section 6 reports the preliminary results of the heuristic evaluation conducted and the identified major usability problems of the system. Finally, conclusions and the future agenda for additional improvements are outlined in Section 7.

\section{RELATED WORK}

\subsection{Teacher's Workstation}

Technological advancements have made the concept of a smart classroom with a technologically-enhanced teacher's workspace feasible. Until recently, a teacher's workstation inside the classroom would primarily comprise a simple desk with a chair. The learning resources available to conduct the lesson, would often include textbooks (containing standard syllabus), relevant exercise books, a laptop in order to support curriculum learning (e.g. share courserelated material, use educational apps, PPT presentations), and personal written notes [27] [7]. Technological advances, however, have proved these resources insufficient and outdated and increased the importance of utilizing technology in the context of a modern classroom [15] [25]. Furthermore, these advances have intensified the need for enhanced and improved teaching resources, considering that their quality directly influences and is instrumental in the teaching effect [24]. Technological mediums such as laptops have become a vital component for educators, enabling increased efficiency in planning and preparation of lessons, supplying active repositories of student work, as well as personalizing learning for students [18].

There are a number of research endeavors that aim to assist teachers and facilitate their educational efforts. Indicatively, an effort to improve teachers' experience is the work in [9], in which biometrics-based login for the teachers is introduced. Combining face-recognition and speaker-verification technologies, the smart classroom is able to identify a teacher automatically and provide an undeterred login experience. A representative example of contributions designed to assist the educator during the teaching process is the system developed in [22]. Tablet PC Presenter enables easy and quick creation of presentations, as it combines the advantages of classical computer presentations with the additional benefits of handwriting. Another topic that has attracted the attention of researchers is "Reflection-in-action", which aims at assisting professionals to reflect on their current performance during actions [21]. The system in [1], called ClassBeacons, aspires to help teachers intuitively reflect-in-action, taking the best and most efficient course of action on dividing time and attention over pupils throughout a lesson. The objective is to successfully support their sense-making of ongoing performance and modification of upcoming actions, without overburdening teaching in an unobtrusive manner.

A plethora of commercial products aiming to support the educator along with the educational process already exist. Indicatively, Bookwidgets [3] is an application for portable devices which enables educators to build interactive exercises in addition to operating any of the predefined educational apps that offer instant grading. Similarly, Classtime [5] is a system that facilitates the creation of personalized quizzes in a variety of disciplines. It also provides immediate feedback on students' level of understanding and comprehension of the teaching materials. Additionally, Schoology [10] is a learning management system that allows teachers to design engaging lessons, provides organizational tools associated with the course, course analytics and statistics of each student. It also facilitates individual feedback for each student, as the teacher can leave personalized comments during grading. Finally, Google Classroom [4] is an easy-to-use tool that helps teachers manage coursework. Educators can create classes, assign homework, grade and send feedback by tracking student progress.

\subsection{Attention Monitoring}

There are several research efforts that address the prevailing need of teachers to monitor student's attention levels and supervise their progress throughout the course. Indicatively, the research in [26] discusses two monitoring tools, NetOp and the Synergo Supervisor. The first enables the teacher to attend each student's desktop and provides an overview of the entire class through thumbnails of students' desktops, while the second is a monitoring tool that provides group data. It allows the monitoring of the class activity, the identification of signs of emerging phenomena, the navigation in different aspects of classroom activities, focusing on different social levels (e.g. individual, group, class), finally guiding the teacher to intervene. Another tool aiming to support student supervision is LECTORviewer [23]. This tool presents a synopsis of the students' attention levels and requires the educator's opinion on ambiguous behaviors or automatically launches interventions.

A respective example of using wearables in the context of supporting the educator within the smart classroom is the work in [6], which addresses the co-design, implementation, and evaluation of a wearable classroom orchestration tool, Lumilo. The system uses mixed-reality smart glasses that augment K-12 teachers' real-time perceptions of their students' learning, metacognition, and behavior as students work with personalized learning software. These systems continuously adapt instruction accordingly to the student's state and need. Research has confirmed that straightforward, live feedback regarding the effectiveness of the teacher's instructional interventions could help them adjust their instruction instantly, as well as gradually improve the instruction [6]. Finally, another wearable tool that assists the teacher in the educational process is NotifEye, a smart watch application whose purpose is to communicate, in a mobile fashion, events that require the teacher's attention during a lesson (e.g., $60 \%$ of students are tired) [23].

\section{DESIGN PROCESS}

The design of LECTOR Podium followed an iterative process. Semistructured interviews and brainstorming sessions were conducted with educators and people with experience in teaching, industrial designers and usability experts. Through these methods, details of an "ideal" workstation (i.e. equipment, functionality, features, characteristics and appearance) envisioned for their classroom were collected. A systematic analysis of the collected data led to the design of a low-fidelity prototype of the teacher's workstation resembling a comfortable and flexible arm-chair. In addition to a comprehensive insight relating to the appearance of the workstation, the participants also provided a collection of requirements about the overall functionality that they would wish this arm-chair to offer. Their comments were constructive, helped in correcting initial design 


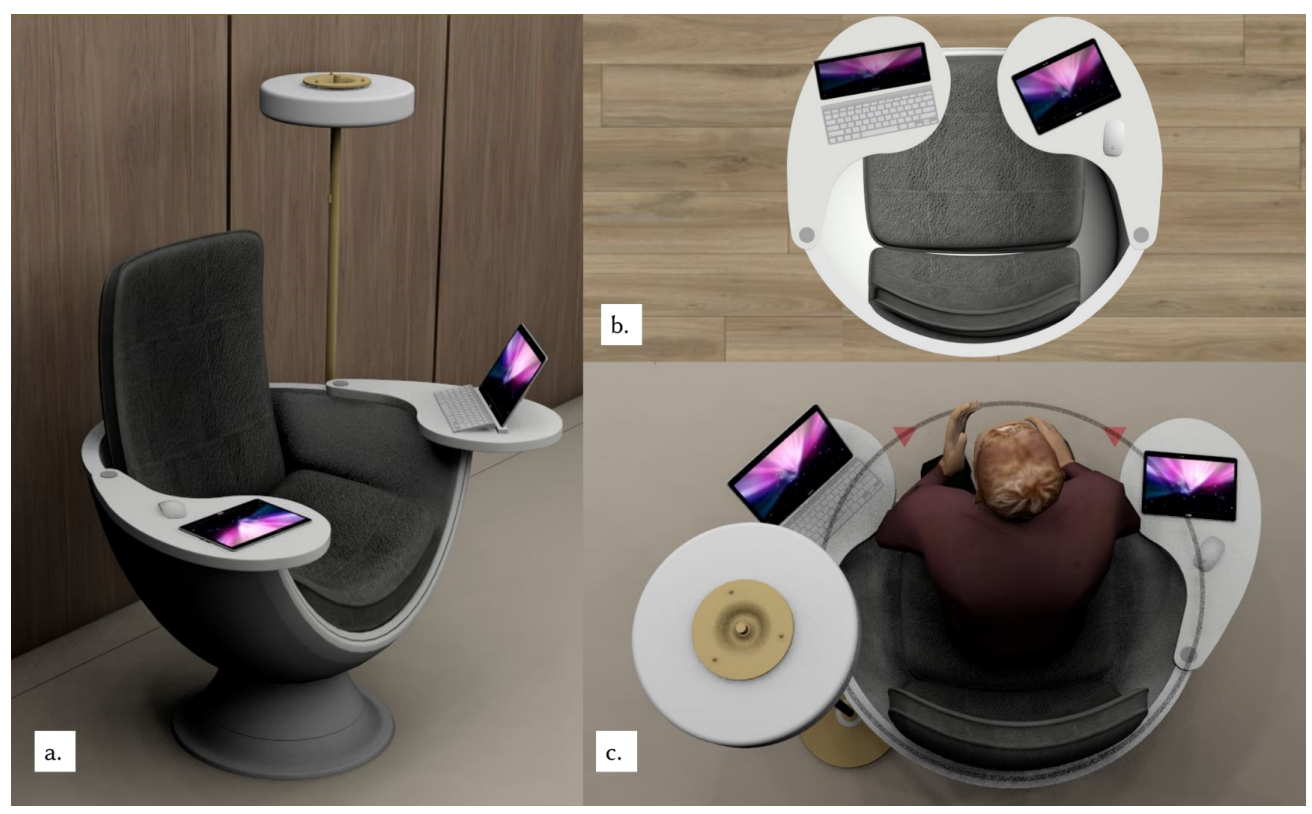

Figure 1: (a) A digital 3D perspective view of the educator's workstation, with arm-rests (b) retracted and (c) extended, $\odot$ FORTHICS 2020

shortcomings and contributed towards the generation of new, innovative ideas leading to an outcome more likely to be acceptable by the end-users. After further modifications, a final assortment of requirements for the intelligent classroom were solicited, leading to the thorough elicitation of the educator's arm-chair system (workstation) requirements. These requirements facilitated the drawing of a preliminary model of the teacher's arm-chair, the creation of a 3D model of the intelligent classroom and the positioning of the relevant artifacts in the environment. Subsequently, a heuristic evaluation of the high-fidelity prototypes for the arm-chair's software by five (5) User Experience (UX) experts, was conducted, as described in section 6, with the objective to assess both the concept and its functionality, as well as to identify potential errors from an usability perspective. Finally, after implementing the design improvements resulting from the evaluation process, the system development followed.

\section{THE EDUCATOR'S WORKSTATION}

LECTOR Podium is located in the Intelligent Classroom of ICSFORTH (http://ami.ics.forth.gr) [9], a simulation space of a real classroom. This classroom features both commercial and custommade interdependent artifacts enhanced with state-of-the-art technologies, capable of exchanging information with each other establishing a unified interaction experience. It is equipped with a wallto-wall projected interactive board, technologically-augmented student desks [20], an assortment of ambient facilities as well as a comfortable workstation for the educator (LECTOR Podium).

One of the fundamental artefacts that support the educator is the designated workstation that facilitates the supervision of the classroom (Figure 1). The educator can monitor and manipulate all features of the Intelligent Classroom from a comfortable workstation, a custom-made "intelligent" arm-chair, containing two embedded tablets and a variety of sensors. The main arm-chair's tablet, located on its left hand side, is attached on a rotating arm, which the educator can manipulate so as to bring the device in front of them or hide it when necessary (Figure 1). This tablet hosts various applications that enable educators to access educational material, get a comprehensive overview of the class (i.e. classroom statistics, attendance, submitted assignments), monitor student attention and provide means for the seamless, unobtrusive supervision of the students and overall management of the educational process. The secondary tablet is embedded on the right armrest, acts as a control center and presents auxiliary information. In particular, it serves as a controller for both the room's conditions (i.e. temperature, humidity, lights) and the numerous intelligent classroom artefacts (i.e. student's desks, board, walls, windows), an application launcher/manager and a secondary display for the main screen. Other features include hidden LED lights (specific events e.g., test are marked with different colors) in order for individual situations to be marked with different colors (i.e. examination, increased levels of inattention), a weight sensor that enables the chair to know if someone is seated and embedded microphones and speakers (i.e. to support voice recognition for voice commands and enable sound notifications aimed at the educator). At the same time, the system can identify the educator through face recognition and location monitoring via smart watch determining their location in the classroom at all times (e.g., to lock or unlock the chair's functionalities).

\section{SOFTWARE INFRASTRUCTURE}

The software architecture of the Intelligent Classroom follows a stack-based model where the first layer, namely the AmI-Solertis 

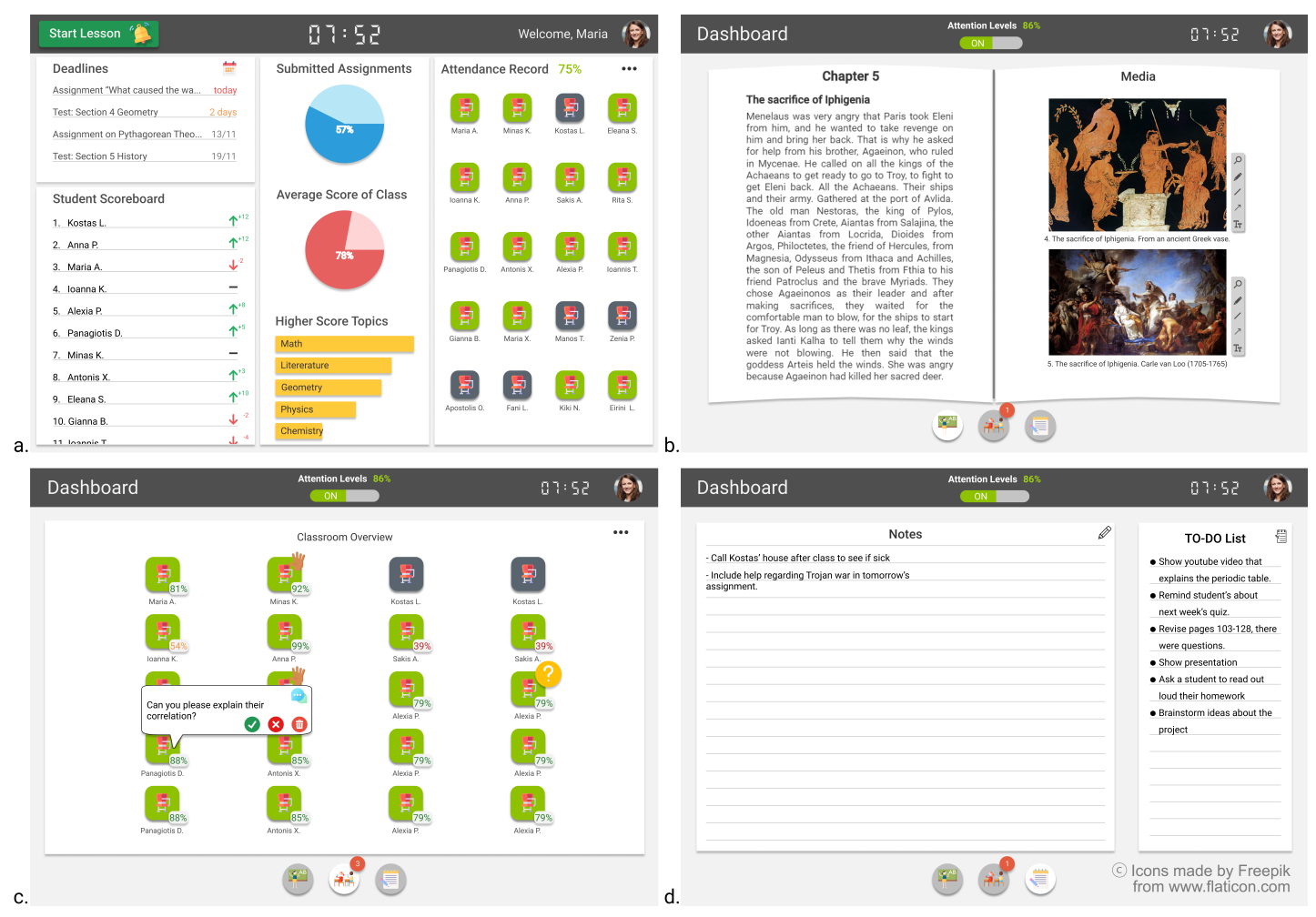

Figure 2: Main tablet Dashboard (a) before the lesson and during the lesson, (b) "Content" tab, (c) "Classroom Overview" tab, (d) "Notes \& TO-DO List", () Icons made by Freepik from www.flaticon.com

middleware infrastructure [11], is responsible for (i) the collection, analysis and storage of the metadata regarding the environment's artifacts and (ii) their deployment, execution and monitoring to create a ubiquitous ecosystem. The next two layers, namely the ClassMATE [12] and the LECTOR [8] frameworks, expose the core libraries and finally the remaining layer contains the end-user applications responsible for delivering educational interventions and accepting user input. As far as the end-user applications are concerned, CognitOS [17] delivers to the students a sophisticated environment for educational applications hosting able to present teachers' interventions, and the CognitOS Classboard [16] deployed on the "Intelligent Classroom Board" - a wall- to-wall projected Interactive board - takes advantage of the facilities offered by the intelligent environment and the amenities stemming from its large dimensions (wall-size), in order to enhance educational activities and provide new educator- and student- oriented experiences.

The software in both the main and secondary tablets of LECTOR Podium contains various applications that assist the teacher in fulfilling their education objectives as well as organize the lesson efficiently. A characteristic example is the main tablet's course dashboard which has two modes, before and during the lesson. In the pre-lesson mode information such as deadlines, attendance record, each student's progress and general course statistics (submitted assignments, average score of class, higher-scoring topics) are available to the educator in order to have a general overview of the class (Figure 2). During the lesson, the teacher has at their disposal three tabs, "Content", "Classroom Overview" and "Notes \& TO-DO List". The first tab contains the course's material (e.g., book, PowerPoint presentation, quiz) which the teacher can also choose to share simultaneously with the interactive board (Figure 2). The interactive board is equipped with a sophisticated algorithm, which is responsible for: (i) Window management and adjusting the applications according to the placement of related applications, (ii) the application with which the user is interacting or interacted last should remain on the foreground and (iii) secondary applications [16]. The other two tabs are for the educator's personal use as they permit him/her to have complete supervision of the classroom, and in conjunction with the "Students" app on the side tablet provide personalized interventions to each student besides holding private notes and reminders about the lesson (Figure 2).

The side tablet operates as a control center for the environment and the ambient artefacts with applications to modify the conditions of the classroom (e.g., lighting, temperature, sound) and to operate the technologically-enhanced artefacts embedded in the classroom (e.g., Wall, Interactive Board, Students' Desks). Moreover, the secondary tablet operates as an application launcher and manager. Some respective examples of applications that LECTOR Podium runs are the "Quiz" (Figure 3), which enables the teacher to launch a fifteen-minute pop-quiz that they have prepared and the "Questions" (Figure 4), in which all written student questions are accumulated in chronological order allowing the educator to accept, reject or discard a question. 

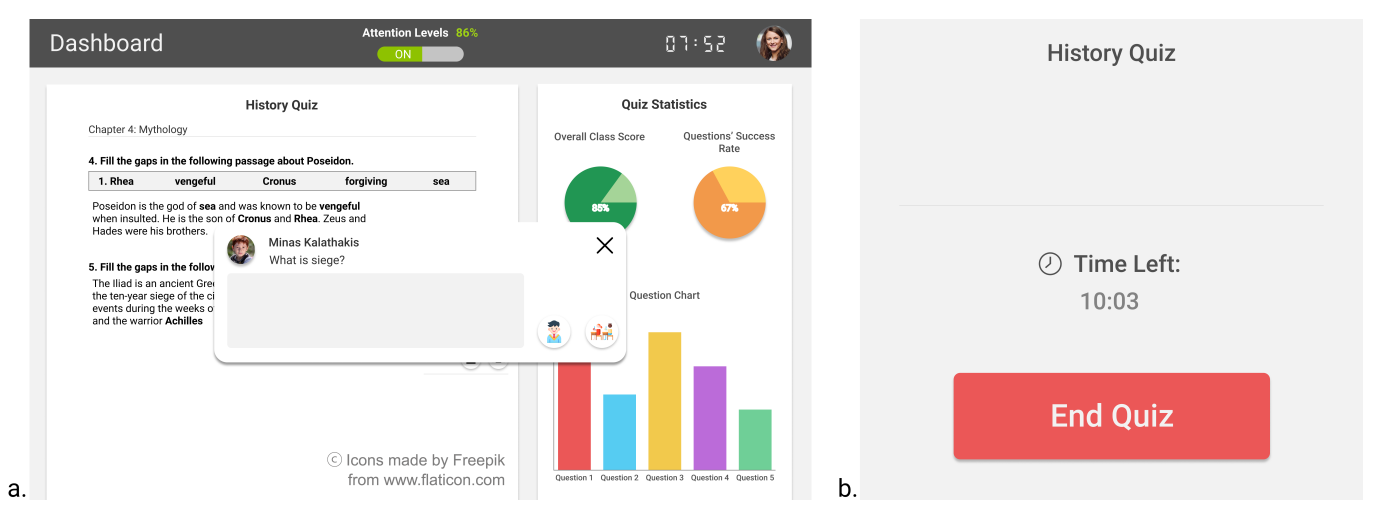

Figure 3: The Quiz application: from the main tablet (a) while a student has made a question and (b) from the side tablet the Quiz application controls, ๑ Icons made by Freepik from www.flaticon.com

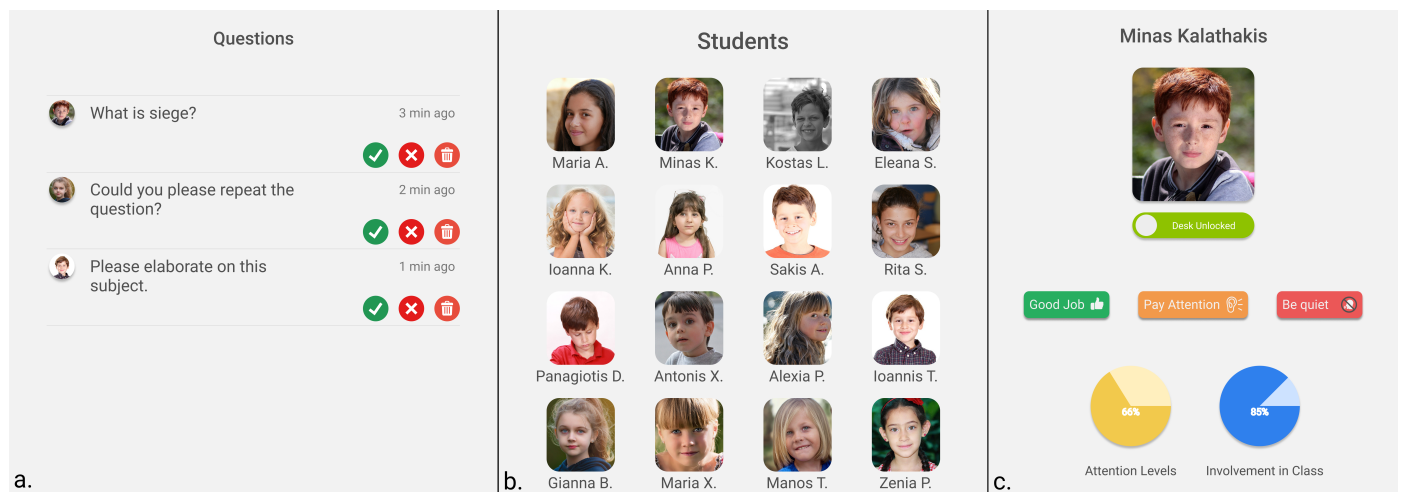

Figure 4: From the "Apps" tab on the side tablet, (a) "Questions", (b) "Students", and (c) the profile of a selected student.

Furthermore, the "Students" application permits the educator to lock/unlock a student's desk and acquire information about their involvement in class and attention levels. In addition, the educator can administer individual pre-defined interventions (Figure 4), for instance "Good Job" or "Pay Attention". Other notable instances of applications are the "Calendar" containing the schedule of the class, the "Attendance" holding each week's attendance record and the "Statistics" accumulating all the relevant class statistics (e.g., score of topics, this week's submitted assignments percentage).

\section{HEURISTIC EVALUATION}

LECTOR Podium was evaluated using the heuristic evaluation method in order to eliminate possible significant usability errors, as part of an iterative design process, before proceeding with user testing. Being the most popular of the usability inspection methods, heuristic evaluation [28] is implemented as a systematic inspection of a user interface design for usability. This evaluation method involves having a small set of evaluators examine the interface and judge its compliance with recognized usability principles, namely "heuristics". Involving three to five evaluators, according to [30], is sufficient since not much additional information is generated by using larger numbers to identify the majority of errors. To ensure independent and unbiased evaluations, each individual evaluator inspects the interface alone and compares it with the "heuristics".
Once all the evaluators have completed the procedure, the discovered usability errors in the interface are accumulated in a list with references to those usability principles that were violated based on the evaluator's judgement. Thereafter, the evaluators are asked to independently provide severity ratings [29] for each problem, ranging from zero ("not a usability problem") to four ("Usability catastrophe"). Finally, each problem is ranked with an ease-of-fix ranking ranging from zero ("would be extremely easy to fix") to three ("would be difficult to fix") by the development team to designate the amount of effort needed to address it.

Five (5) User Experience (UX) experts examined the interface of the LECTOR Podium and assessed its compliance with the "heuristics". The investigation uncovered 30 usability issues out of which 15 were rated as cosmetic problems only, 8 were identified as minor usability problems, and the remaining 7 were ranked as major issues (Figure 5). The 15 major and minor usability problems have been prioritized in the list below, with the most severe and hardest to fix problems listed first.

\subsection{Severity 3}

- How the scale and the points of the student score board are calculated is hard to understand (ease of fix: 2) 


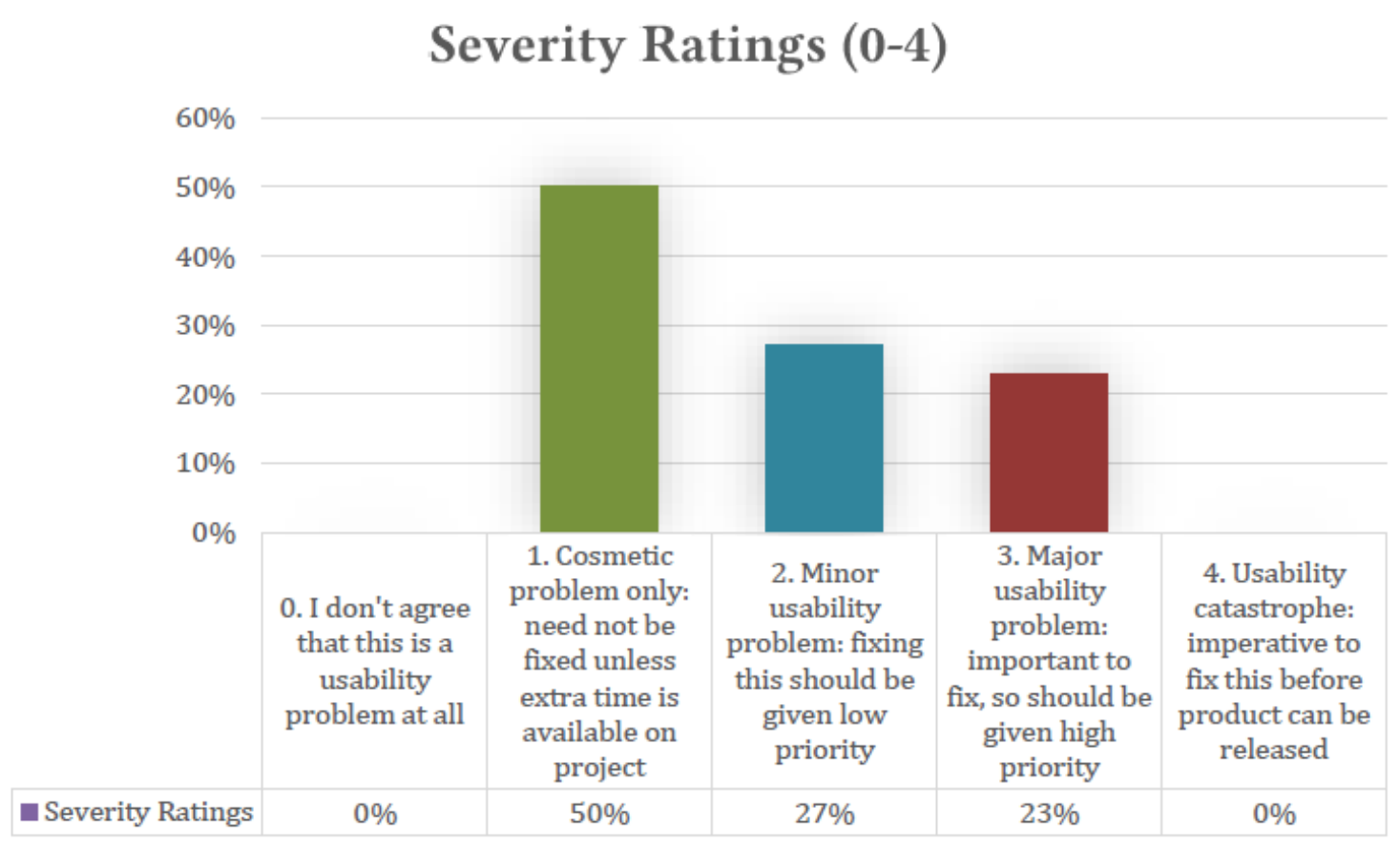

Figure 5: Chart with the percentages of the usability problems per severity rating.

- The submitted assignments percentage and average score of class are not displayed in a coherent manner (ease of fix: 2)

- Discard and cancel options in written questions are ambiguous (ease of fix: 1)

- The functionality of the unlock button in the student page is not distinct (ease of fix: 1 )

- A save/undo changes option should be offered (ease of fix: 1)

- The period of the "attention levels" and "involvement in class" charts is ambiguous (ease of fix: 1)

- Not clear how to enable the options for highlighting, adding text and crossing text (ease of fix: 0 )

\subsection{Severity 2}

- When the teacher edits an image the "send" button is ambiguous, as it is not clear if the students will receive the image or the board (ease of fix: 1)

- Not clear that the answers of the quiz display the correct one and are not clickable (ease of fix: 1)

- The buttons in the control page and their functionality are ambiguous as it is not clear when some are enabled/disabled (ease of fix: 1)

- Not clear that the students are shown based on their seating in class (ease of fix: 0 )

- A close or back button to return to all apps should be provided in all applications (ease of fix: 0)

- In classroom overview it is not clear where the teacher is positioned in relation to the actual classroom plan (ease of fix: 0)
- A score/percentage beside each higher score topic should be displayed (ease of fix: 0 )

- Student attendance should be displayed in numbers and not in percentage (ease of fix: 0 )

\section{CONCLUSION \& FUTURE WORK}

This work equips the Intelligent Classroom of ICS-FORTH with a state-of-the-art educator's workstation, named LECTOR Podium, which enables the educator to monitor and operate every aspect of the intelligent classroom from a comfortable, flexible and technologically-enhanced arm-chair. The system takes advantage of the ambient intelligent facilities in order to create a unified interaction experience in an unobtrusive manner and reinforce the educational process. In addition, LECTOR Podium software hosts various applications that support the teacher's objectives and focus on improving student-teacher communication (e.g., personalized interventions).

The heuristic evaluation which was conducted with UX experts, revealed various usability issues, which will be resolved for the next version, to be used to conduct a user-based evaluation of the system in real conditions with the targeted end-users, educators, as well as students.

\section{ACKNOWLEDGMENTS}

This work is supported by the FORTH-ICS internal RTD Program 'Ambient Intelligence and Smart Environments'. Moreover, the authors would like to thank Antonis Prinianakis for his collaboration during the development of functional prototype that connected 
the teacher's workstation with student desks and Emmanouil Stamatakis for the 3D model creation.

\section{REFERENCES}

[1] An, P., Bakker, S., Ordanovski, S., Taconis, R., Paffen, C.L. and Eggen, B. 2019 ClassBeacons: Enhancing Reflection-in-Action of Teachers through Spatially Distributed Ambient Information. Extended Abstracts of the 2019 CHI Conference on Human Factors in Computing Systems (2019), 1-4.

[2] Bagheri, M. and Movahed, S.H. 2016. The Effect of the Internet of Things (IoT) on Education Business Model. 2016 12th International Conference on Signal-Image Technology Internet-Based Systems (SITIS) (Nov. 2016), 435-441.

[3] BookWidgets - The perfect content creation tool for teachers in the classroom: https://www.bookwidgets.com/. Accessed: 2020-08-06.

[4] Classroom: manage teaching and learning: https://edu.google.com/products/ classroom/. Accessed: 2020-08-06

[5] Classtime: The clear path to student success: https://www.classtime.com/. Accessed: 2020-08-06.

[6] Holstein, K., Hong, G., Tegene, M., McLaren, B.M. and Aleven, V. 2018. The classroom as a dashboard: co-designing wearable cognitive augmentation for K-12 teachers. Proceedings of the 8th international conference on learning Analytics and knowledge (2018), 79-88.

[7] Horsley, M. and Sikorová, Z. 2014. Classroom teaching and learning resources: International comparisons from TIMSS-A preliminary review. Orbis scholae. 8 2 (2014), 43-60.

[8] Korozi, M., Antona, M., Ntagianta, A., Leonidis, A. and Stephanidis, C. 2017 LECTORstudio: creating inattention alarms and interventions to reengage the students in the educational process. Proceedings of the 10th Annual International Conference of Education, Research and Innovation (2017).

[9] Korozi, M., Stefanidi, E., Samaritaki, G., Prinianakis, A., Katzourakis, A., Leonidis, A. and Antona, M. 2019. Shaping the Intelligent Classroom of the Future. International Conference on Human-Computer Interaction (2019), 200-212.

[10] Learning Management System | LMS | Schoology: https://www.schoology.com/ homepage. Accessed: 2020-08-06.

[11] Leonidis, A., Arampatzis, D., Louloudakis, N. and Stephanidis, C. 2017. The AmISolertis system: Creating user experiences in smart environments. 2017 IEEE 13th International Conference on Wireless and Mobile Computing, Networking and Communications (WiMob) (Oct. 2017), 151-158.

[12] Leonidis, A., Margetis, G., Antona, M. and Stephanidis, C. 2010. ClassMATE: enabling ambient intelligence in the classroom. World Academy of Science, Engineering and Technology. 66, (2010), 594-598.

[13] Marquez, J., Villanueva, J., Solarte, Z. and Garcia, A. 2016. IoT in Education Integration of Objects with Virtual Academic Communities. New Advances in
Information Systems and Technologies (Cham, 2016), 201-212.

[14] Mikre, F. 2011. The roles of information communication technologies in education: Review article with emphasis to the computer and internet. Ethiopian fournal of Education and Sciences. 6, 2 (2011), 109-126.

[15] Mioara, M.S. 2012. The impact of technological and communication innovation in the knowledge-based society. Procedia-Social and Behavioral Sciences. 51, (2012), 263-267.

[16] Nikitakis, G., Ntagianta, A., Korozi, M., Leonidis, A., Antona, M. and Stephanidis, C. 2020. THE COGNITOS CLASSBOARD: SUPPORTING THE TEACHER IN THE INTELLIGENT CLASSROOM. INTED2020 Proceedings. (2020), 3361-3371.

[17] Ntagianta, A., Korozi, M., Leonidis, A., Antona, M. and Stephanidis, C. 2018. CognitOS: A Student-Centric Working Environment for an Attention-Aware Intelligent Classroom. HCI International 2018 - Posters' Extended Abstracts (Cham, 2018), 102-110.

[18] Parr, J.M. and Ward, L. 2011. The Teacher's Laptop as a Hub for Learning in the Classroom. Fournal of Research on Technology in Education. 44, 1 (Sep. 2011), 53-73. DOI:https://doi.org/10.1080/15391523.2011.10782579.

[19] Romeo, G. 2008. Information and communication technologies in education. Rethinking Education with ICT: New directions for effective practices. Rotterdam, Sense publishers. (2008).

[20] Savvaki, C., Leonidis, A., Paparoulis, G., Antona, M. and Stephanidis, C. 2013. Designing a Technology-Augmented School Desk for the Future Classroom. HCI International 2013 - Posters' Extended Abstracts (Berlin, Heidelberg, 2013), 681-685.

[21] Schon, D.A. 1984. The reflective practitioner: How professionals think in action. Basic books.

[22] Shi, Y., Xie, W., Xu, G., Shi, R., Chen, E., Mao, Y. and Liu, F. 2003. The smart classroom: merging technologies for seamless tele-education. IEEE Pervasive Computing. 2 (2003), 47-55.

[23] Stefanidi, E., Korozi, M., Leonidis, A., Doulgeraki, M. and Antona, M. EducatorOriented Tools for Managing the Attention-Aware Intelligent Classroom.

[24] Tai, Y., Wushuo, Y. and Kun, S. 2017. Explore the medical curriculum teaching development in the smart classroom. International fournal of Information and Education Technology. 7, 2 (2017), 130.

[25] Tinio, V.L. 2003. ICT in Education. e-ASEAN Task Force.

[26] Voyiatzaki, E. and Avouris, N. 2014. Support for the teacher in technologyenhanced collaborative classroom. Education and Information Technologies. 19, 1 (2014), 129-154.

[27] Wang, X., Li, M. and Li, C. 2019. Smart Classroom: Optimize and Innovative-Based on Compared with Traditional Classroom. International fournal of Information and Education Technology. 9, 10 (2019).

[28] Heuristic Evaluation: How-To: Article by Jakob Nielsen.

[29] Severity Ratings for Usability Problems: Article by Jakob Nielsen.

[30] Why You Only Need to Test with 5 Users. 